\title{
A Evolução da Paisagem nas Áreas de Mineração no Município de Santos, Litoral Sul do Estado de São Paulo
}

\author{
The Evolution of Landscape in Mining Areas in the \\ Municipality of Santos, South Coast of the State of São Paulo
}

\author{
La Evolución del Paisaje en las Áreas de Minería en el \\ Municipio de Santos, Litoral Sur del Estado de São Paulo
}

\author{
Técia Regiane Bérgamo ${ }^{1}$ \\ Universidade Estadual de Campinas e \\ Universidade Metropolitana de Santos, Brasil \\ Regina Célia de Oliveira ${ }^{2}$ \\ Universidade Estadual de Campinas, Brasil
}

\begin{abstract}
Resumo
O termo paisagem apresenta uma variação conceitual dentro da ciência geográfica. Neste trabalho abordaremos o enfoque antropogênico a respeito dos problemas das modificações e transformações ocorridas na paisagem devido às atividades de mineração no município de Santos. A mineração consiste numa atividade essencial para o progresso e desenvolvimento econômico. No entanto a atividade apresenta diversos impactos levando a alteração e a degradação da paisagem. O presente trabalho busca realizar uma leitura da paisagem, verificando as mudanças temporais ocorridas desde a década de 1960 aos dias atuais nas áreas de mineração, buscando identificar o estado de desenvolvimento das modificações graduais ocorridas ao longo do período, propondo assim, uma reflexão a respeito do desenvolvimento sustentável das atividades de mineração existentes no município de Santos. A leitura comparativa entre as imagens de satélite de escalas temporais diferentes foi realizada por meio do NDVI (Índice de Vegetação por Diferença Normalizada) dos anos de 1986 e
\end{abstract}

1 UNICAMP e UNIMES correo electrónico: tecia.bergamo@unimes.br

2 UNICAMP correo electrónico: reginacoliveira@ige.unicamp.br

Este artículo corresponde a la ponencia presentada en el 35th Conference of Latin American Geographers realizada en San José, Costa Rica del 20 al 22 de mayo del 2018. 
Técia Regiane Bérgamo, Regina Célia de Oliveira. The Evolution of Landscape in Mining Areas in the Municipality of Santos, South Coast of the State of São Paulo

2017. A aerofoto do ano de 1962 mostra o processo de ocupação, porém os resultados comparativos do NDVI dos anos de 1986 e 2017 demonstraram uma recuperação natural da área. A esse processo natural, cabe a discussão sobre capacidade da área degradada em retornar a condição estável em conformidade com os valores ambientais, estáticos e sociais do entorno.

Palavras chave: Paisagem, Mineração, Degradação, Desenvolvimento Sustentável.

\begin{abstract}
The term landscape presents a conceptual variation within geographic science. In this work we will focus on the anthropogenic approach to the problems of changes and transformations in the landscape due to mining activities in the municipality of Santos. Mining is an activity essential to economic progress and development. However the activity presents several impacts leading to the alteration and the degradation of the landscape. The present work seeks to make a reading of the landscape, verifying the temporal changes that occurred from the 1960 s to the present day in the mining areas, seeking to identify the state of development of the gradual changes that occurred throughout the period, thus proposing a reflection on the of the sustainable development of existing mining activities in the municipality of Santos. The comparative reading between the satellite images of different time scales was performed using the NDVI (Normalized Difference Vegetation Index) for the years 1986 and 2017. The 1962 aerodrome shows the occupation process, but the comparative results of the NDVI from the years 1986 and 2017 demonstrated a natural recovery of the area. To this natural process, it is a question of the capacity of the degraded area to return to the stable condition in accordance with the environmental, static and social values of the environment.
\end{abstract}

Keywords: Landscape, Mining, Degradation, Sustainable Development.

\title{
Resumen
}

El término paisaje presenta una variación conceptual dentro de la ciencia geográfica. En este trabajo abordaremos el enfoque antropogénico respecto a los problemas de las modificaciones y transformaciones ocurridas en el paisaje debido a las actividades de minería en el municipio de Santos. La minería consiste en una actividad esencial para el progreso y el desarrollo económico. Sin embargo la actividad presenta diversos impactos llevando la alteración y la degradación del paisaje. El presente trabajo busca realizar una lectura del paisaje, verificando los cambios temporales ocurridos desde la década de 1960 a los días actuales en las áreas de minería, buscando identificar el estado de desarrollo de las modificaciones graduales ocurridas a lo largo del período, proponiendo así, una reflexión al respecto del desarrollo sostenible de las actividades mineras existentes en el municipio de Santos. La lectura comparativa entre las imágenes satelitales de escalas temporales diferentes fue realizada por medio del NDVI (Índice de Vegetación por Diferencia Normalizada) de los años 1986 y 2017. El aerofoto del año 1962 muestra el proceso de ocupación, pero los resultados comparativos del año, NDVI de los años 1986 y 2017 demostraron una recuperación natural del área. A este proceso natural, cabe la discusión sobre capacidad del área degradada en retornar la condición estable de conformidad con los valores ambientales, estáticos y sociales del entorno.

Palabras clave: Paisaje, Minería, Degradación, Desarrollo sostenible. 
Técia Regiane Bérgamo, Regina Célia de Oliveira. A Evolução da Paisagem nas Áreas de Mineração no Município de Santos, Litoral Sul do Estado de São Paulo

\section{Introdução}

A crescente expansão socioeconômica, realizada pela urbanização acelerada, devido ao desenvolvimento dos setores industriais, agrícolas e de serviços, e do crescimento populacional, entre outros, tem aumentado a busca por recursos naturais e em especial, por recursos minerais (Rufino et al., 2008).

Os recursos minerais são bens importantes para o desenvolvimento econômico e indispensável para a sociedade moderna e a Baixada Santista apresenta um potencial significativo para a extração de recursos minerais.

Dentro de um prognóstico de potencialidade, é necessário levar em conta os condicionantes de mercado e as restrições ambientais, além da viabilidade. Para a viabilidade da produção de areia industrial dependerá de cada área ou depósito investigado, com os estudos específicos de caracterização físico-química e tecnológica das areias, bem como da análise de viabilidade técnico-econômica e ambiental da lavra e beneficiamento para a implantação da mina (Instituto de Pesquisas Tecnológicas do Estado de São Paulo, 2015).

As substâncias minerais mais produzidas e relacionadas ao consumo doméstico são principalmente aquelas que são utilizadas como agregados na construção civil (Bueno, 2010).

Segundo o Anuário Mineral Brasileiro (2005) os agregados são materiais granulares, sem forma e volume definidos, de dimensões e propriedades para uso em obras de engenharia civil. São considerados agregados às pedras britadas, o cascalho e as areias naturais ou obtidas por britagem de rocha, além dos substitutivos, como os obtidos de resíduos inertes reciclados, as escórias de aciaria e os agregados industriais, entre outros.

Os agregados são divididos em dois grupos, sendo os agregados naturais que se encontram de forma particulada na natureza, como a areia, o cascalho ou pedregulho; e os agregados artificiais que são aqueles produzidos por algum processo industrial, como as pedras de britas, as areias artificiais, as escórias de alto-forno e argilas expandidas, entre outros (La Serna e Rezende, 2013).

\section{Areia para construção civil}

Os depósitos de areia são resultado da concentração de grãos de quartzo pelo seu transporte e deposição por agentes naturais de intemperismo, a partir de rochas preexistentes, gerando acumulações com maior 
ou menor concentração do minério e outros minerais de média a elevada dureza e implicando em diferença de dificuldades nas técnicas de extração e recuperação ambiental (Bueno, 2010 p.26).

A região de Santos tem um potencial para a exploração de pedra britada e areia para a construção civil, sendo que o que se falta é o disciplinamento sobre os locais, o modo de extração que contemple o meio ambiente, formas de recuperação das áreas lavradas e desativadas (Duarte, 1990).

A areia consiste em uma substância mineral de desagregação de diversos tipos de rochas encontradas em vários tipos de depósitos, como aluviões e coluviões (Vieira e Rezende, 2015).

A areia é extraída de leito de rios, várzeas, depósitos lacustres e mantos de decomposição de rochas, sendo que muitas empresas e extração são familiares, de pequeno porte. No Brasil, $90 \%$ são provenientes de leitos de rios (Tunes, 2001).

Na Baixada Santista os depósitos de areia para a construção civil estão relacionados basicamente de coberturas sedimentares cenozoicas, em especial os depósitos arenosos flúvio-coluviais e marinhos praiais atuais e pré-atuais (Instituto de Pesquisas Tecnológicas do Estado de São Paulo, 2015).

Existem na região dois tipos de exploração de areia. A areia que sofre processo de lavagem e seleção granulométrica para a sua comercialização, que é destinada para a construção civil e a outra que são simplesmente retiradas dos rios, que são comercializadas sem lavagem ou seleção, que são chamadas de "areias impuras" (Duarte, 1990).

A antiga Extratora de Areia Sandi realizava a extração por meio de draga móvel.

Na situação de extração de areia em leito de rio, a draga bombeia a areia e outros materiais presentes no fundo do rio, utilizando a água como veículo. A areia bombeada fica depositada na draga ou é enviada através de tubulações diretamente ao silo, enquanto que a água retorna 20 ao rio juntamente com sedimentos finos. O volume de água bombeado é praticamente todo devolvido ao rio, com exceção de uma pequena parcela agregada a areia (Santos, 2008).

\section{Área de Estudo}

A área de estudo está inserida na Região Metropolitana da Baixada Santista (RMBS). 
Técia Regiane Bérgamo, Regina Célia de Oliveira. A Evolução da Paisagem nas Áreas de Mineração no Município de Santos, Litoral Sul do Estado de São Paulo

Figura 1: Localização da área.

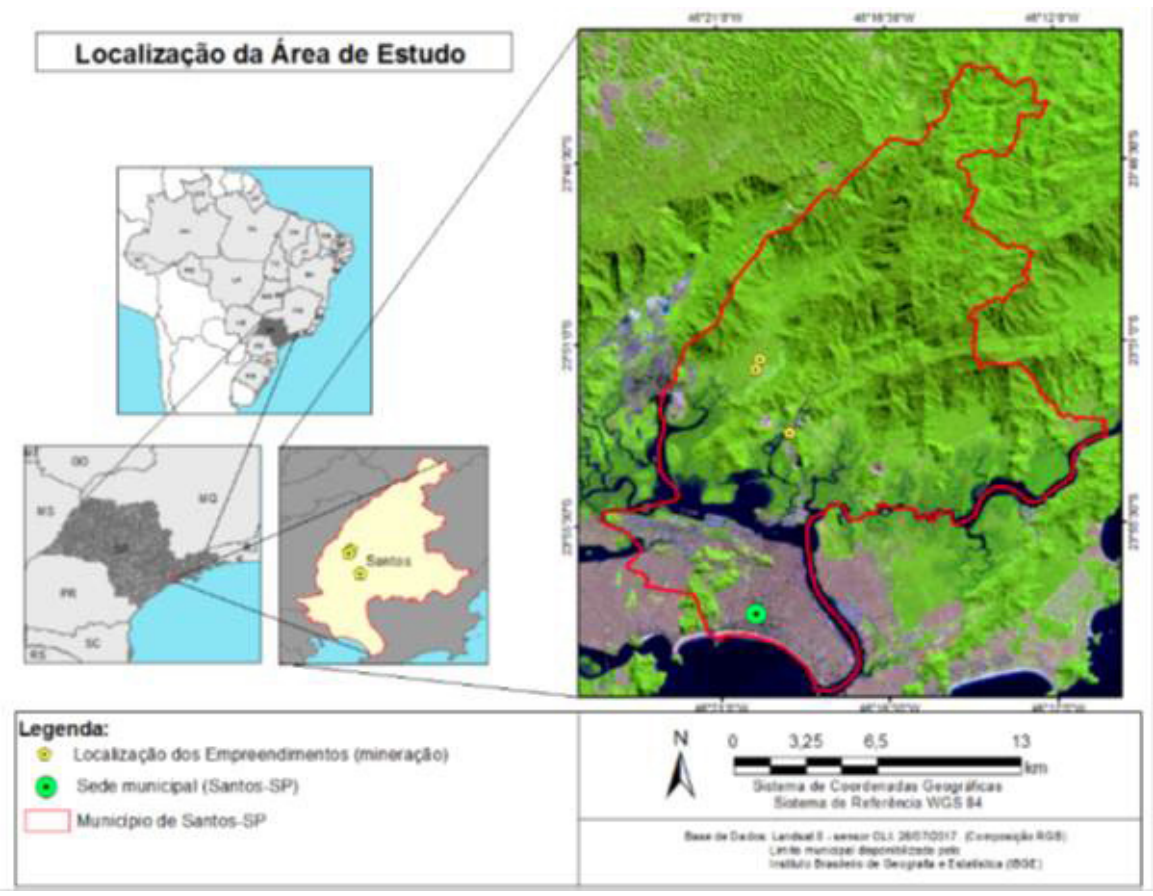

Fonte: Elaborada por Bérgamo, 2018.

No primeiro momento foi realizado um pré-campo na área da antiga Extratora de Areia Sandi LTDA, na Estrada Piaçaguera, Km 73, as margens do Rio Jurubatuba, sob as coordenadas geográficas $23^{\circ} 53^{\prime} 12.02^{\prime \prime S}$; $46^{\circ} 19^{\prime} 7.35^{\prime \prime} \mathrm{O}$.

A região está localizada na porção central do litoral paulista, caracterizada por uma região altamente urbanizada e populosa devido ao crescimento econômico ligado às atividades industriais que se concentram no município de Cubatão, às portuárias que estão situadas em Santos e ao turismo que envolve todos os municípios, não incluí somente Cubatão pelo fato de não apresentar as praias (Afonso, 2005).

Segundo Ferreira (2002) a área se encontra paralisada desde o ano de 1988. A areia para construção civil era realizada por dragagem no rio e apresenta desequilíbrio no perfil hidráulico do rio, desaparecimento de ilhotas, mudança do leito do rio, turbidez da água, assoreamento, erosão das margens, vegetação extirpada. 
Técia Regiane Bérgamo, Regina Célia de Oliveira. The Evolution of Landscape in Mining Areas in the Municipality of Santos, South Coast of the State of São Paulo

\section{A desativação de empreendimentos mineiros}

A desativação de um empreendimento mineiro apresenta um destaque que envolve as questões socioambientais e político-econômicas (Reis e Barreto, 2000).

A desativação ambientalmente segura e socialmente responsável de minas e instalações conexas demanda planejamento concatenado com o plano de extração, em paralelo a uma cuidadosa planificação econômico-financeira, elementos ainda virtualmente ausentes no setor mineral brasileiro.

A desativação de uma área minerada corresponde à preparação para a paralisação das atividades, e requer um planejamento específico seguindo o que foi detalhado no PRAD (Sánchez, 2008). O PRAD é o plano ou o projeto de recuperação de áreas degradadas, que teve sua origem na Constituição Federal de 1988 e em seguida pelo Decreto-Lei n. 97.632/89, que regulamentou a Lei n.6938/81da Política Nacional do Meio Ambiente, obrigando a recuperação da área degradada decorrente das atividades de mineração.

Em relação ao aspecto legal, uma legislação mais específica voltada tanto para o minerador como para o poder público poderia contribuir para a questão da responsabilidade a respeito da reparação dos danos ambientais gerados de áreas de mineração que se encontram abandonadas.

Nas áreas que ocorreram o encerramento das atividades e se reconhece o titular da área levanta-se uma discussão jurídica da possibilidade legal de exigir do antigo titular a reabilitação ambiental da área (Reis e Barreto, 2000), porém muitas áreas são consideradas órfãs, assim verifica-se a necessidade de uma legislação mais clara visando à harmonia entre a atividade mineral e o meio ambiente.

Nas questões sociais apontamos sobre a necessidade do bem mineral para a sociedade moderna, porém a extração de recursos minerais apresenta um antagonismo, pois de um lado a atividade beneficia a sociedade, do outro lado à atividade apresenta o conflito em relação ao uso e ocupação da área, bem como os diversos impactos ambientais.

Quanto ao aspecto político-econômico é necessário não somente o planejamento das áreas de mineração, mas um sistema de gestão desde o início da extração do bem mineral até o encerramento da atividade.

Segundo Sánchez (2007), o planejamento e a gestão ambiental na indústria de mineração integram um campo em rápida evolução. Há certamente avanços importantes em temas como: recuperação de áreas 
degradadas, manejo de águas em minas, monitoramento ambiental e relações com a comunidade. Porém, estes avanços são distribuídos de forma desigual, um reflexo da grande diversidade do setor mineral. Esta diversidade ocorre em escala mundial e se repete no Brasil, país onde a desigualdade é um traço marcante.

Outro ponto relevante é que, se há avanços notáveis no planejamento de novas minas e na gestão ambiental dos empreendimentos em funcionamento, ainda há um longo caminho a se percorrer no tratamento das questões socioambientais associadas ao fechamento de minas. O quadro legal e o aparato administrativo foram montados para equacionar os problemas ambientais decorrentes da abertura e do funcionamento de minas e demais atividades, mas muito pouco foi feito para tratar da situação incontornável de que minas exauridas são indústrias que ficam obsoletas e fecham (Sánchez, 2001).

Segundo Bitar, Fornasari e Vasconcelos (1988), no processo extrativo, a restauração da área é algo impossível de acontecer, pois restaurar significa reproduzir as condições exatas do local, tais como eram antes de alteradas. A reabilitação parece ser a resposta mais próxima da realidade, porque a reabilitação está ligada a ideia de uso e ocupação do solo, predefinida de acordo com um projeto de reutilização do local minerado: lazer, residencial, industrial, entre outros. Quanto à recuperação implica, em aplicar técnicas no local alterado, de modo que as condições ambientais acabem se situando próximas às condições anteriores à intervenção.

Um plano de fechamento indica medidas capazes de reparar os danos ambientais e recuperar ambientes degradados, possibilitando assim o uso futuro com segurança na área desativada, buscando atenuar os impactos socioeconômicos e mantendo os benefícios sociais a comunidade (Neri e Sánchez, 2012).

No dia 24 de março do ano de 2018 realizamos um pré-campo, e identificados alguns impactos ambientais na área desativada. 
Técia Regiane Bérgamo, Regina Célia de Oliveira. The Evolution of Landscape in Mining Areas in the Municipality of Santos, South Coast of the State of São Paulo

Figura 2: Processos erosivos.

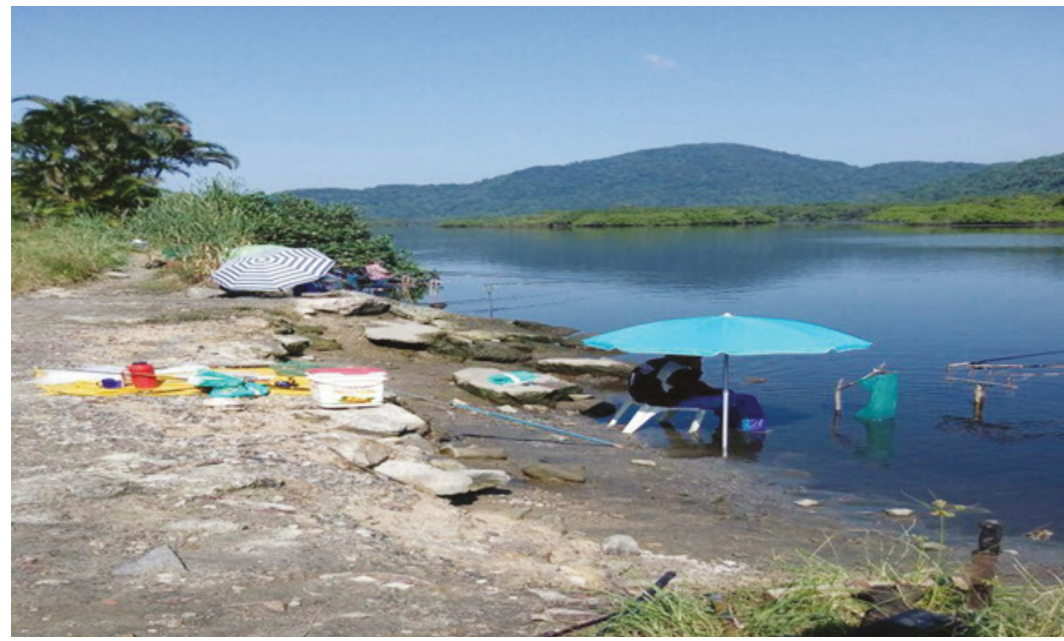

Fonte: Bérgamo, 2018.

Os impactos ambientais apresentados no local consistem na impermeabilização do solo na margem direita do rio pela construção das vias de circulação de veículos automotores, construção de estrada, a supressão da vegetação.

Figura 3: Manguezal

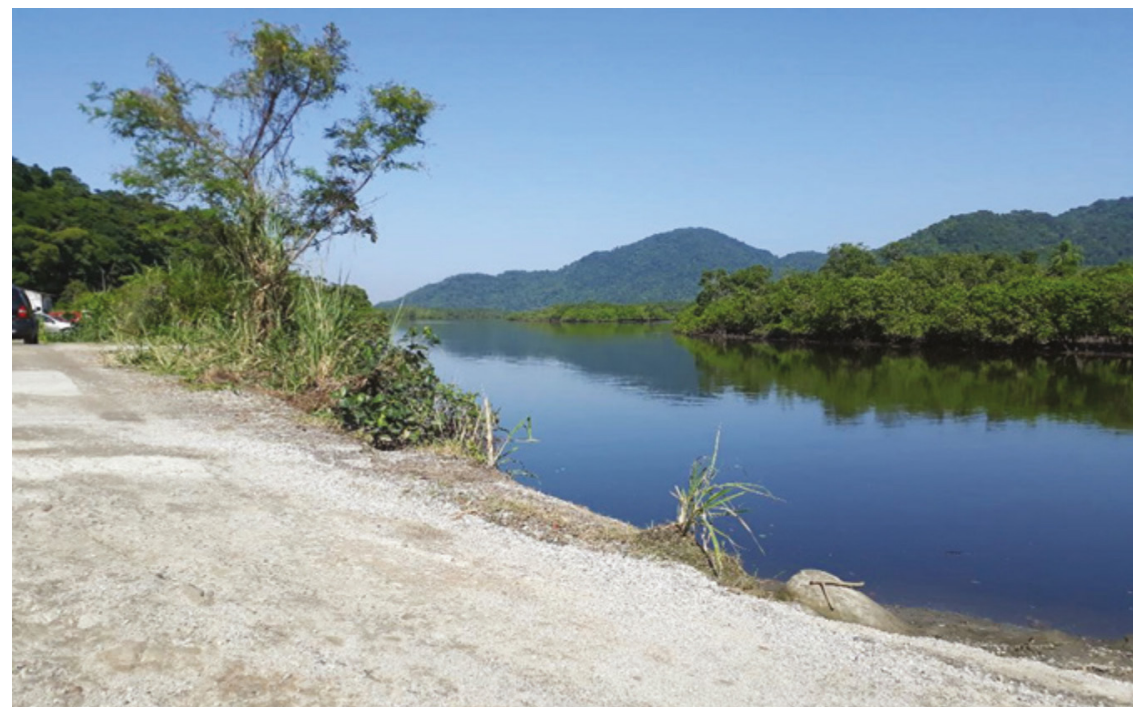

Fonte: Bérgamo, 2018.

544 Revista Geográfica de América Central No 61E (3) Especial CLAG Este artículo está bajo una licencia

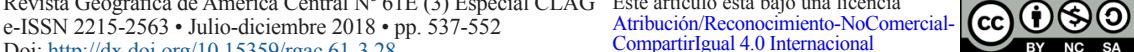
Doi: http://dx.doi.org/10.15359/rgac.61-3.28 
Técia Regiane Bérgamo, Regina Célia de Oliveira. A Evolução da Paisagem nas Áreas de Mineração no Município de Santos, Litoral Sul do Estado de São Paulo

Na margem esquerda do rio o manguezal é contínuo.

Ainda a margem direita do rio o cenário é apresentado por uma estrutura de vegetação herbáceo, arbustiva com algumas espécies exóticas, como goiabeira, coqueiro, entre outros, além de uma construção abandonada.

Figura 4: Espécies exóticas

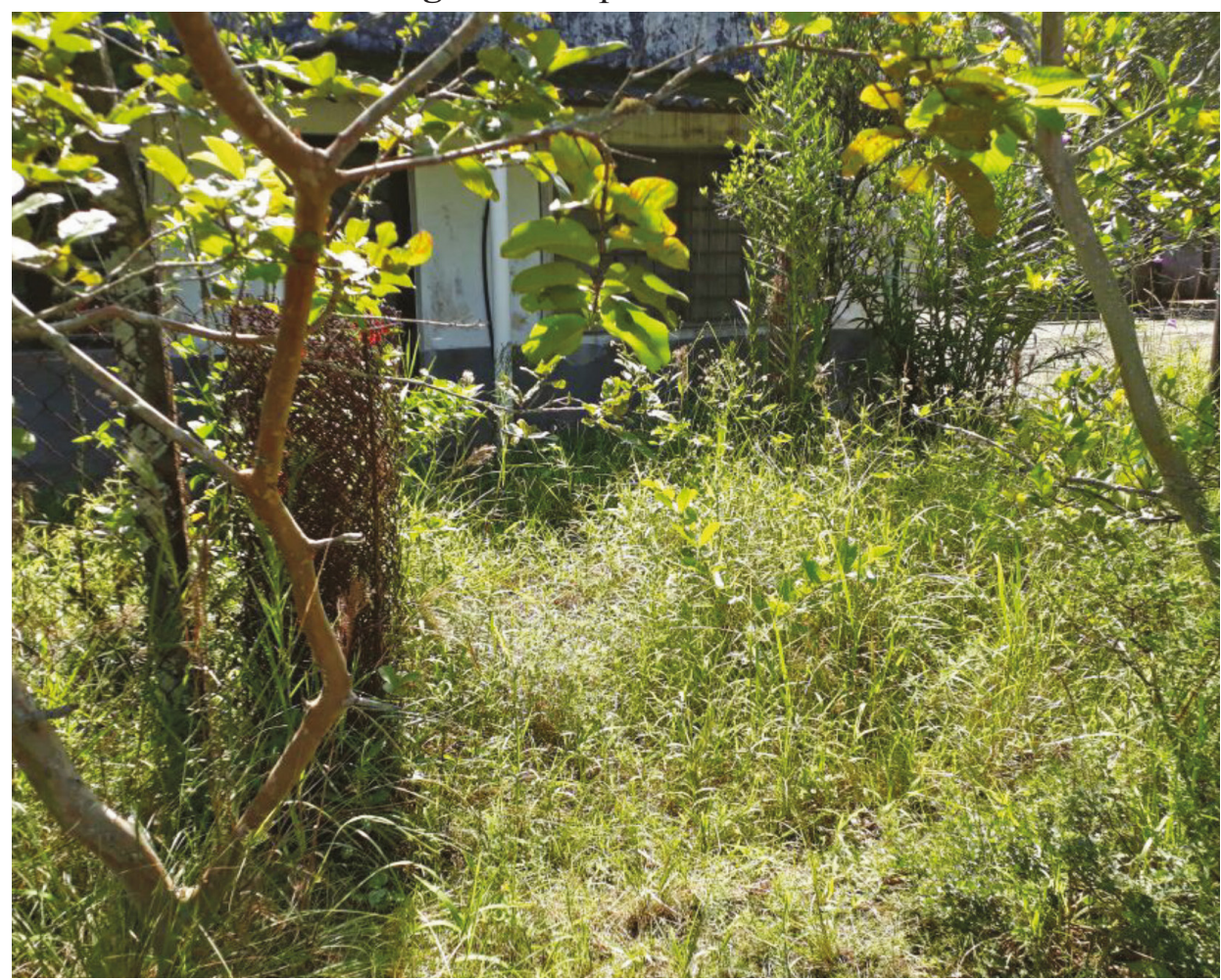

Fonte: Bérgamo, 2018.

\section{Índice de Vegetação por Diferença Normatilizada-NDVI e Pro- cedimentos Metodológicos}

No primeiro momento realizamos um pré-campo para o conhecimento da área, em seguida foi realizado o processamento das imagens.

As etapas dos procedimentos metodológicos estão representadas na Figura 5. Os processamentos das imagens foram realizados em ambiente SIG (Sistema de Informações Geográficas). A calibração radiométrica foi feita de acordo com Markham; Baker (1987) e a reflectância espectral 
Técia Regiane Bérgamo, Regina Célia de Oliveira. The Evolution of Landscape in Mining Areas in the Municipality of Santos, South Coast of the State of São Paulo

obtida conforme propõe Allen et al. (2002). A Tabela1 apresenta a descrição do NDVI (Índice de Vegetação por Diferença Normalizada). Destaca-se ainda que na análise da área de estudo foi utilizada uma aerofoto do ano de 1962, a imagem foi adquirida na Secretaria da Agricultura do Estado de São Paulo - Instituto Agronômico.

Figura 5: Fluxograma referente aos procedimentos metodológicos.

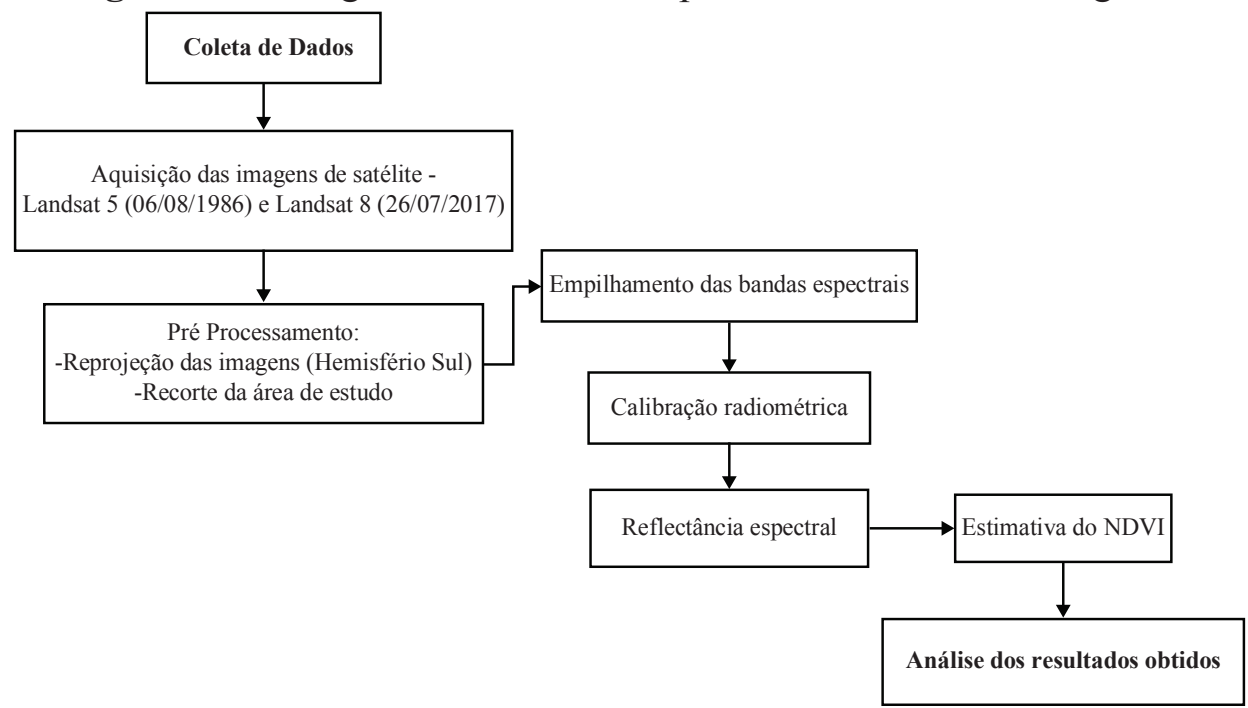

Fonte: Bérgamo, 2018. 
Técia Regiane Bérgamo, Regina Célia de Oliveira. A Evolução da Paisagem nas Áreas de Mineração no Município de Santos, Litoral Sul do Estado de São Paulo

Tabela 1: Descrição do Índice de Vegetação por Diferença Normalizada.

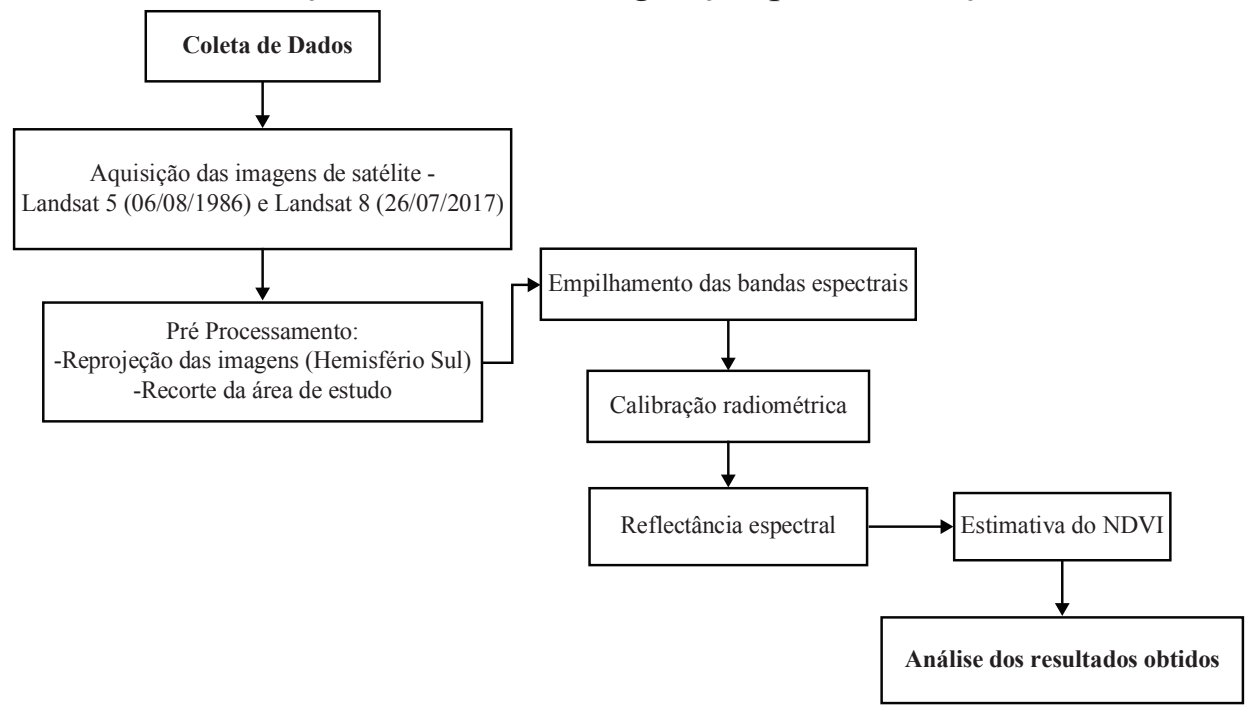

\section{A recuperação da área degradada}

A reabilitação parece ser a resposta mais próxima da realidade, porque a reabilitação está ligada a ideia de uso e ocupação do solo, predefinida de acordo com um projeto de reutilização do local minerado: lazer, residencial, industrial, entre outros (Bitar; Fornasari; Vasconcelos 1988).

Atualmente a área está sendo utilizada para o uso da pesca esportiva, assim, este trabalho tem como justificativa a necessidade de reabilitação da área com uma infraestrutura que venha contribuir para a comunidade de forma segura e a recuperação da área degradada.

O termo recuperação tem sido utilizado atualmente no sentido de que se promova a revegetação da área degradada com a preocupação de uma elevada diversidade de espécies nativas, visando à sustentabilidade do ecossistema (Martins, 2014).

A respeito do aspecto ambiental, uma medida importante consiste em ampliar os estudos sobre o reflorestamento, dando suporte ao minerador. No estado de São Paulo, temos a Resolução SMA-21, de 21-11-2001 da Secretaria do Meio Ambiente, que fixa a orientação para o reflorestamento heterogêneo. Com a necessidade da revisão periódica foi implantada a Resoluções SMA-47, de 26-11-2003 e SMA-8, de 31-1-2008, buscando contribuir para a recuperação das áreas degradadas; outra Resolução 
Técia Regiane Bérgamo, Regina Célia de Oliveira. The Evolution of Landscape in Mining Areas in the Municipality of Santos, South Coast of the State of São Paulo

é a SMA-32, de 3-4-2014, que apresenta uma orientação com diretrizes e critérios para a restauração ecológica. Estas resoluções consistem num grande avanço científico para os projetos de restauração ecológica, com destaque para a listagem das espécies arbóreas com a indicação do bioma/ ecossistema de ocorrência natural no Estado de São Paulo.

No sentido de ampliar os estudos sobre os melhores critérios para a recuperação florestal cabe também um estudo mais detalhado do solo, uma vez que dentro de um bioma existem diversos tipos de solo, cada um com suas especificidades, contribuindo assim para aperfeiçoar o reflorestamento, otimizando os custos e períodos da recuperação das áreas degradadas.

\section{Resultados}

O NDVI (Índice de Vegetação por Diferença Normatlizada) consiste em um índice geralmente utilizado pela comunidade científica para estudos globais, regionais e locais (WARDLOW e EGBERT, 2008).

Figura 6: Aerofoto de Santos - SP no ano de 1962.

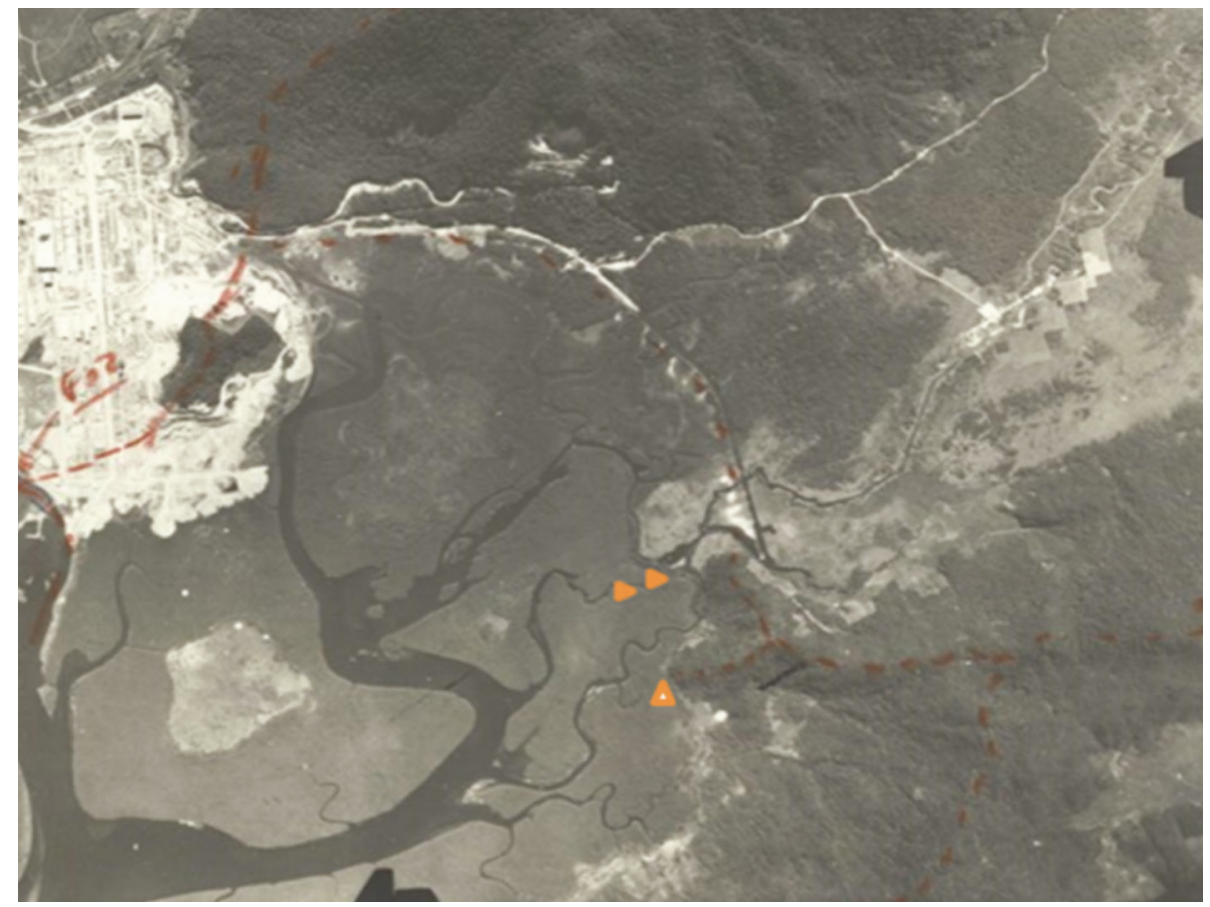

Fonte: Secretaria da Agricultura do Estado de São Paulo- Instituto Agronômico, 1962. 
Técia Regiane Bérgamo, Regina Célia de Oliveira. A Evolução da Paisagem nas Áreas de Mineração no Município de Santos, Litoral Sul do Estado de São Paulo

Figura 7: Mapa do NDVI do município de Santos-SP nas datas de 06/08/1986 e 26/07/2017.

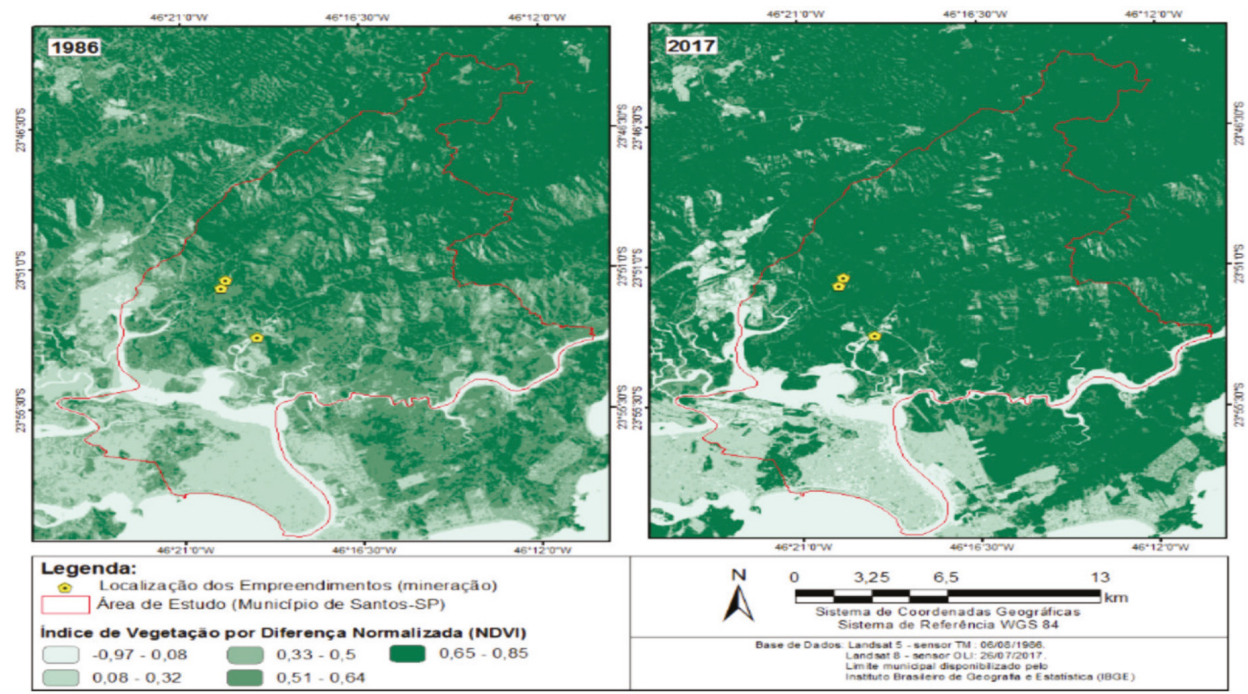

Figura 8: Histograma de frequência dos valores do NDVI referente as datas de 06/08/1986 e 26/07/2017.
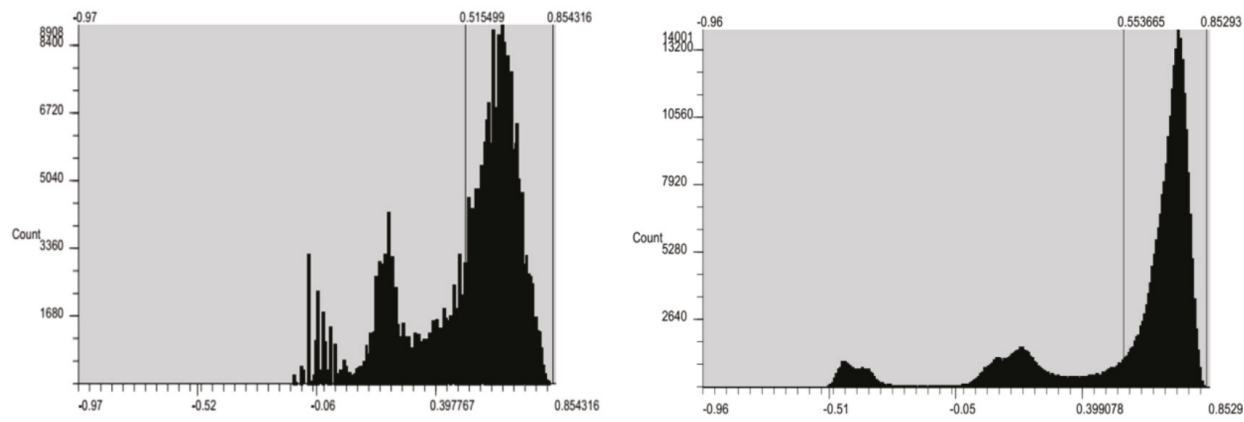
Técia Regiane Bérgamo, Regina Célia de Oliveira. The Evolution of Landscape in Mining Areas in the Municipality of Santos, South Coast of the State of São Paulo

Tabela 2: Estatísticas descritiva do NDVI referente às duas datas analisadas

\begin{tabular}{|c|c|c|}
\hline Data & Estatistica Descritiva & NDVI \\
\hline \multirow{5}{*}{$\begin{array}{l}\stackrel{0}{\infty} \\
\stackrel{\infty}{\infty} \\
\stackrel{\infty}{0} \\
\stackrel{0}{0}\end{array}$} & Mínimo & $-0,97$ \\
\hline & Máximo & 0,85 \\
\hline & Média & 0,51 \\
\hline & Moda & 0,64 \\
\hline & Desvio padrão & 0,21 \\
\hline \multirow{5}{*}{ 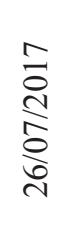 } & Mínimo & $-0,96$ \\
\hline & Máximo & 0,85 \\
\hline & Média & 0,55 \\
\hline & Moda & 0,73 \\
\hline & Desvio padrão & 0,31 \\
\hline
\end{tabular}

A aerofoto do ano de 1962 mostra o processo de ocupação, porém os resultados comparativos do NDVI dos anos de 1986 e 2017 demonstraram uma recuperação natural da área. A esse processo natural, cabe a discussão sobre capacidade da área degradada em retornar a condição estável em conformidade com os valores ambientais, estáticos e sociais do entorno. A análise da densidade da cobertura vegetal e sua evolução espaço-temporal contribuem para o diagnóstico do dinamismo dos espaços costeiros.

\section{Considerações Finais}

A esse processo natural de revegetação cabe a discussão sobre capacidade da área degradada em retornar a condição estável em conformidade com os valores ambientais, estáticos e sociais do entorno. A análise da densidade da cobertura vegetal e sua evolução espaço-temporal contribuem para o diagnóstico do dinamismo dos espaços costeiros.

Quanto a questão das áreas desativadas pela extração mineral, cabe-se uma discussão entre os órgãos ambientais municipais e os empreendedores mineiros para que ocorra uma mudança de atitude que venha conciliar a proteção ambiental e a qualidade de vida da comunidade do entorno. 
Técia Regiane Bérgamo, Regina Célia de Oliveira. A Evolução da Paisagem nas Áreas de Mineração no Município de Santos, Litoral Sul do Estado de São Paulo

\section{Referências}

Afonso, C.M. (2005). Transformação ambiental e paisagística na Baixada Santista, SP. Paisagem Ambiente: ensaios. n. 20 - São Paulo - p. 85 - 130.

Allen, R. G.; Terezza, R.; Tasumi M. (2002). Surface energy balance algorithms for land. Advance training and user's manual, version 1.0, p. 98.

Anuário Mineiro Brasileiro. (2005). Brasília: DNPM, v. 34. 426 p.

Bitar, O. Y, Fornasari Filho, N. e Vasconcelos, M. M. T. (1988). Considerações básicas para a abordagem do meio físico nos estudos de impacto ambiental. In: CONGRESSO BRASILEIRO DE GEOLOGIA, 35., 1988, Belém. Anais. Belém: SBG. p. 1974-1982.

Bueno, R. I. S. (2010). Aproveitamento da areia gerada em obra de desassoreamento - caso: Rio Paraibuna / SP. Dissertação (Mestrado). Escola Politécnica da Universidade de São Paulo. São Paulo: Departamento de Engenharia de Minas e de Petróleo. 109 p.

Duarte, U. (1990). Geologia para planejamento de uso e ocupação territorial - exemplo Santos Continente. Tese apresentada ao concurso de livre docência junto ao departamento de geologia econômica e geofísica aplicada do Instituto de Geociências da Universidade de São Paulo. São Paulo: DEDALUS Acervo IG.

Ferreira, C.J. Cadastro geral de áreas mineradas. (2002). In: Souza, C.R. de G. (coord.): Projeto SIIGAL - Sistema Integrador de Informações Geoambientais para o Litoral do Estado de São Paulo, aplicado ao gerenciamento costeiro. Instituto Geológico. [Online]. Disponível em: <https://goo.gl/LFpZjp> . [Acesso em: 04 de fevereiro de 2018].

Huete, A. R. (1988). A soil-adjusted vegetation index. Remote Sensing of Environment, Elsevier Science Publishing Co., New York, USA. v. 25, p. 295-309.

La Serna, H. A.; Rezende, M. M. (2013). Agregados para a construção civil. DNPM. [Online]. Disponível em: <http://www.dnpm.gov.br/ dnpm/publicacoes/serie-estatisticas-e-economia-mineral/outras-publicacoes-1/8-1-2013-agregados-minerais $>$. [Acesso em 03 de fevereiro de 2018].

Markham, B. L., Barker, J. L. (1987). Thematic mapper band pass solar exoatmospherical irradiances. International Journal of Remote Sensing, v. 8, n. 3, p.517-523. 
Técia Regiane Bérgamo, Regina Célia de Oliveira. The Evolution of Landscape in Mining Areas in the Municipality of Santos, South Coast of the State of São Paulo

Martins, S. V. (2014). Recuperação de áreas degradadas: como recuperar áreas de preservação permanente, voçorocas, taludes rodoviários e áreas de mineração. Viçosa, MG: Aprenda Fácil.

Neri, A. C. e Sánchez, L. E. (2012). Guia de boas práticas de recuperação ambiental em pedreiras e minas de calcário. São Paulo: ABGE-Associação Brasileira de Geologia de Engenharia e Ambiental.

Reis, N. L dos. e Barreto, M. L. (2001). Desativação de empreendimento mineiro no Brasil. São Paulo: Signus Editora.

Rouse, J.W.; Haas, R.H.; Schell, J.A.; Deering, D.W. (1973). onitoring vegetation systems in the Great Plains with ERTS. NASA SP-351 I, 309-317.

Rufino, A. C. S., Farias, M. S. S. e Dantas Neto, J. (2008). Avaliação qualitativa da degradação ambiental provocada pela mineração de areiaregião do médio curso do rio Paraíba. Espírito Santo do Pinhal: Engenharia Ambiental, Espírito Santo do Pinhal, v. 5, n. 1, p. 47-64.

Sánchez, L. E. (2008). Avaliação de impacto ambiental: conceitos e métodos. São Paulo: Oficina de Textos.

Sánchez, L. E. (2001). Desengenharia: o passivo ambiental na desativação de empreendimentos industriais. São Paulo: EDUSP. 254 p.

Sánchez, L. E. (2007). Mineração e meio ambiente. In: Tendências tecnológicas Brasil 2015: geociências e tecnologia mineral. Ed. por Francisco Rego Chaves Fernandes et al. Rio de Janeiro: CETEM/MCT. Parte 2, capítulo 6, p. 191-208.

Santos, D. N. (2008). Extração de areia e dinâmica sedimentar no alto curso do rio Paraná na região de Porto Rico, PR. Dissertação de mestrado, Universidade Guarulhos, Guarulhos, SP.

Instituto de Pesquisas Tecnológicas do Estado de São Paulo IPT. Ordenamento Territorial Geomineiro da Região Metropolitana da Baixada Santista, Estado de São Paulo. (2015). Relatório Técnico n. 142577 -205 i/ xi. São Paulo: Secretaria de Energia- SEE.

Tunes, M. R. (2001). Visão governamental Brasileira. In: Seminário Internacional sobre agregados para construção civil: o futuro da mineração de agregados. Campinas, SP. ANEPAC-Associação Nacional das Entidades de Produtores de Agregados para Construção Civil.

Vieira, E. G e Rezende, E. N. (2015). Exploração Mineral de Areia e um Meio Ambiente Ecologicamente Equilibrado: É possível conciliar? Sustentabilidade em Debate - Brasília, v. 6, n. 2, p. 171-192. 